\title{
A TRADUÇÃO NO ENSINO/APRENDIZAGEM DE LATIM: UMA ANÁLISE DAS DIVERSAS NOMEAÇÕES DO TEXTO TRADUZIDO
}

\author{
Danielle Chagas de Lima* \\ Universidade Estadual de Campinas
}

\begin{abstract}
Resumo: O presente trabalho tem por objetivo examinar a tradução como ferramenta didática no percurso de ensino/aprendizado de latim. Considerando-se a grande atenção que tem sido destinada às abordagens e metodologias no ensino de latim, gostaríamos de olhar mais especificamente para a tradução e suas relações com o processo de leitura à luz dos Estudos da Tradução, de modo a verificar as possíveis particularidades do ato tradutório no ensino/aprendizado de latim. Desse modo, pensando nas traduções produzidas no processo de ensino/aprendizagem da língua latina e entendendo-as também como processo de uma leitura e produto de um sujeito, buscamos analisar determinadas adjetivações feitas no campo dos Estudos Clássicos à tradução (que tem sido denominada ora tradução de serviço, ora de referência, ora operacional ou de estudo) e suas possíveis implicações. Palavras-chave: Latim. Ensino/Aprendizagem. Tradução.
\end{abstract}

\section{TRANSLATION IN TEACHING/LEARNING LATIN: AN ANALYSIS OF SEVERAL NOMINATIONS OF THE TRANSLATED TEXT}

\begin{abstract}
This paper aims at examining the translation as a didactic tool in teaching/learning Latin. Taking into account the great attention that has been devoted to approaches and methodologies in teaching Latin, we would like to look specifically at translation and its relations with
\end{abstract}

\footnotetext{
* Doutoranda em Linguística pelo Instituto de Estudos da Linguagem, desenvolve pesquisa em Estudos Clássicos com financiamento da Capes. Instituto de Estudos da Linguagem (IEL-Unicamp). E-mail: daniness.lima@gmail.com
} 
the reading process in light of Translation Studies by verifying the possible particularities of the translational act of teaching/learning Latin. Therefore, by regarding the translations produced in teaching/learning Latin language and also understanding them as a reading process and a product of an individual, we intend to analyze certain adjectivizations made in the field of Classical Studies of translation (which sometimes has been called working translation, sometimes reference translation and operational or study translation) and its possible implications.

Keywords: Latin. Teaching/Learning. Translation.

\section{Introdução}

Quando tratamos da tradução de textos clássicos, que são em sua maioria literários e, muitas vezes, textos poéticos, não é raro encontrar discussões acerca do ato tradutório. Em geral, essas discussões costumam problematizar questões relativas à tradução poética, à tradução literal, à fidelidade e às equivalências de sentido, entre outras ${ }^{1}$. No entanto, a discussão sobre o ato tradutório aparece menos no âmbito do ensino/aprendizagem de latim, no qual, a despeito das metodologias empregadas e objetivos do aprendizado, a tradução está, com frequência, presente. Com efeito, a didática de latim se pautou, durante muito tempo, no chamado Método Gramática-Tradução (MGT) e, ainda que hoje o estudo da língua se dê, em muitos casos, por meio de uma abordagem textual de ensino, tendo como foco a leitura, a tradução ainda é uma atividade essencial no aprendizado.

Tendo em vista, então, o fato de que lidar com a tradução é inerente ao estudo da língua latina (e ao trabalho dos classicistas, poderíamos dizer), independentemente das abordagens e metodologias de ensino, é interessante observar o modo como ela é concebida nesse contexto. No âmbito pedagógico, a tradução pode aparecer, para alguns autores, como recurso de análise metalinguística, contexto em que nem sempre é designada como tradução. Todavia,

${ }^{1}$ Vide VASCONCELLOS, 2011. 
a tradução pode ser o meio pelo qual se interpreta os textos, materializando uma leitura. Por fim, a tradução pode ser essencialmente a atividade à qual se dedicam aqueles que finalizaram seus estudos, promovendo o acesso aos textos em nossa língua e, como veremos, somente nesse caso é considerada "tradução propriamente dita" ${ }^{2}$, até mesmo porque aqui extrapola o campo didático.

Considerando a presença e as facetas da tradução quanto ao ensino/aprendizado de latim, observar as diversas nomenclaturas atribuídas ao ato tradutório como exercício didático parece necessário a fim de refletir sobre certas crenças quanto à tradução que permanecem ainda solidificadas nesse contexto.

\section{A tradução no Ensino/Aprendizado de Latim}

Historicamente, a tradução de textos sempre foi o objetivo do ensino de LCs e, para tanto, a metodologia enfocava o ensino da gramática; tratava-se da abordagem estrutural, supramencionada, cuja metodologia ficou conhecida como "gramática-tradução", conforme nomeiam Fortes e Prata (2015, p. 93) ou ainda MGT. Essa metodologia se fundamenta na memorização de vocabulário e na tradução de frases isoladas. No entanto, houve muitas mudanças em relação à metodologia e à abordagem do ensino de língua latina, de onde decorre que o texto - e não frases isoladas - e a leitura em si passaram a ser foco na didática da língua latina e a tradução é ferramenta de apoio à leitura dos textos.

No que concerne às visões de tradução no contexto pedagógico, o estudo de Fernandes (2010) é um dos únicos trabalhos que aborda a questão da tradução no ensino do latim de modo mais detalhado, e apresenta uma descrição bastante abrangente das concepções e do papel da tradução (instrumento ou finalidade) em variados manuais sobre a língua latina. A autora se dedica à análise das concepções

\footnotetext{
${ }^{2}$ É importante ressaltar que a ideia de "tradução propriamente dita" ecoa Jakobson, que define: "A tradução interlingual ou tradução propriamente dita consiste na interpretação dos signos verbais por meio de alguma outra língua”. (JAKOBSON, 2008, p. 64. Grifo nosso.)
} 
de tradução em dezoito manuais de ensino de língua latina, bem como de seu papel na metodologia de cada um deles. Segundo ela, é possível observar diferentes concepções de tradução no ensino de latim, havendo autores que procuram discutir tal assunto em suas obras (FERNANDES, 2010, p. 141). No entanto, ainda que apresentada de maneiras diversas, para Fernandes há uma compreensão comum acerca de tal atividade:

No geral, podemos dizer que os autores entendem a tradução como a descoberta do sentido do texto, que começa na análise das palavras e proposições da frase e culmina no "arranjo" do que eles chamam de tradução literal (diríamos palavra por palavra) numa tradução mais fluente ou tradução literária. [...] Analisando os passos de tradução recomendados pelos autores dos manuais, podemos perceber que o sentido do texto latino deve ser captado pelo aluno, é algo que está ali no texto para ser descoberto e passado à língua materna. (FERNANDES, 2010, p. 143.)

No entanto, ao se contestar a ideia de leitura como descoberta de sentido e com as mudanças metodológicas na didática de latim, que deixou de lado, em grande medida, abordagens estruturalistas focadas na competência linguística - estruturas gramaticais -, a tradução passa a ser ferramenta na abordagem textual de ensino, que privilegia o contato com os textos e não frases isoladas. Desse modo, os alunos são expostos desde o início dos estudos a textos geralmente adaptados ou, algumas vezes, originais ou com poucas modificações, a fim de adquirir a competência de leitura, processo em que a tradução, nos parece, atua como materialização dos sentidos produzidos pelos alunos. Métodos como o Aprendendo Latim e o Latinitas, de Amarante (2015) ${ }^{3}$, são materiais que levam em conta as

\footnotetext{
${ }^{3} \mathrm{O}$ autor recebeu o prêmio Capes de Tese 2014, na área de Estudos Clássicos, pela tese Dois tempos da cultura escrita em latim no Brasil: o tempo da produção e o tempo da conservação - discursos, práticas, representações, proposta metodológica, na qual apresenta o Latinitas.
} 
relações entre leitura e tradução, apresentando textos anteriormente aos aspectos gramaticais que, com o auxílio do professor e de vocabulários, além das intuições linguísticas dos próprios estudantes, são traduzidos a partir do primeiro contato com a língua. Amarante, por exemplo, destaca que seu método tem por objetivo enfatizar, dentre outros aspectos, as atividades de "viii) enfatizar os trabalhos de leitura e tradução; ix) considerar a interpretação como primeira fase da tradução" (AMARANTE, 2013, p. 196. Grifos nossos).

Embora a didática latina, atualmente, busque conferir maior atenção à leitura dos textos, processo ligado em grande medida ao ato tradutório, quando tratamos da tradução com fins pedagógicos no estudo de latim, um interessante aspecto a ser observado é a frequente especificação do termo a fim de diferir a tradução propriamente dita da tradução tida como um exercício de leitura ou de estudo. Nesse contexto, portanto, aparecem notadamente "complementos" ao termo tradução, tais como tradução de serviço, tradução de referência e tradução de estudo.

\section{As nomeações da tradução no ensino/aprendizagem de latim}

Essa particularização do termo no âmbito do ensino/aprendizado de latim tem se dado, sobretudo, no que concerne ao ato tradutório como uma ferramenta de aprendizado da língua relacionado a dois aspectos: competência linguística e competência de leitura a partir de abordagens textuais de ensino. A proposta metodológica de Longo (2006; 2011), por exemplo, discute a importância do texto original no aprendizado de latim e, do ponto de vista da autora, é interessante trabalhar o texto sem quaisquer adaptações. No entanto, o texto trabalhado com o aluno vem apresentado com uma versão ${ }^{4}$ ou tradução de referência (elaborada pelo professor),

4 Em algumas partes de seu método, Amarante também usa versão por tradução, aparentemente para evitar o emprego desse último termo. 
acompanhada do original latino, cujo intuito é auxiliar o aluno a compreender o texto latino, sobretudo a contraposição entre os dois sistemas. Vejamos como a tradução é entendida pela autora:

O que se está chamando aqui de tradução é, mais precisamente, uma "tradução de referência", i.e., o resultado de uma prática metalinguística em que se busca transpor os componentes léxico e morfossintático do latim para o português a fim de ajudar o leitor a ter uma primeira compreensão o texto. Ela não é, portanto, um equivalente formal do texto poético, uma tradução propriamente dita. Para os propósitos deste método, quanto mais a tradução puder preservar do original, mais ela cumpre com as suas finalidades. (LONGO, 2014, p. 185. Grifos nossos.)

A finalidade da tradução aqui é mediar a análise linguística, necessária aos alunos, segundo Longo, para que compreendam o texto. Além disso, percebemos que a tradução deve preservar o original tanto quanto possível, aproximando-se das formas do texto latino, a fim de auxiliar a compreensão do contexto, do vocabulário e de estruturas da língua que devem ser trabalhadas no ensino (LONGO, 2014, p. 184). A justificativa de Longo em relação ao exercício metalinguístico é a dificuldade que se tem em ler o latim em latim de modo tão fluente quanto em outras LMs e, por isso, a prática metalinguística possibilita a compreensão do texto num nível superficial, mas "por falta de termo mais preciso está-se chamando tradução" (LONGO, 2011, p. 175; 2014, p. 186). ${ }^{5}$

Também em Amarante encontramos uma especialização do termo tradução no ensino/aprendizagem de latim:

\footnotetext{
${ }_{5}^{5}$ Essa concepção também se encontra em outros trabalhos de Longo, para quem a leitura, no nível inicial do aprendizado, está sujeita a "uma versão para o português" (LONGO, 2006, P. 75), ou seja, a um exercício de metalinguagem. Segundo ela, "o despretensioso correspondente vernáculo, ao qual se chega com os conhecimentos de morfossintaxe e a consulta ao dicionário, visa apenas possibilitar o entendimento da estrutura sintática da frase latina. Não se deve confundir essa prática com aquilo que se entende por tradução. (LONGO, 2006, p. 75)
} 
Por tradução de estudo, também chamada de tradução operacional, estamos considerando uma versão do texto para o português que se aproxima da forma de elaboração do texto latino. Em outras palavras, trata-se de uma designação para diferenciá-la da tradução propriamente dita, que é resultado de um trabalho mais complexo e que envolve um maior domínio tanto da língua de partida ou língua fonte (o latim) quanto da língua de chegada ou língua meta (em nosso caso, o português). (AMARANTE, 2013, p. 244, nota 33. Grifos nossos.)

Vemos nesses autores um interesse em deixar claro que a tradução para fins pedagógicos é diferente de uma tradução, uma vez que é meio para alcançar outros objetivos, e não um fim em si mesma. É preciso especificar suas funções e objetivos, que, de forma geral, devem mediar a compreensão do texto pelo aluno no nível linguístico e, por isso, em geral é uma tradução "literal”, que se aproxima do original.

Ao tratar da tradução como ferramenta didática ${ }^{6}$, Pegenaut (1996) expõe algumas das funcionalidades no ensino/aprendizagem de LEs. Para ele, o emprego da tradução com esse fim facilita "uma decodificação mais rápida e eficaz das estruturas e de elementos linguísticos" (1996, p. 122), bem como maior controle da compreensão e das interferências da língua materna e, nos níveis iniciais, só deve ser empregada a fim de explicar aspectos linguísticos do texto $^{7}$. A leitura nesse momento é vista apenas como decodificação das formas. Entretanto, o autor indica que, quando os alunos possuem maior domínio da língua, a tradução serve para "comprovar a compreensão do texto” (PEGENAUT, 1996, p. 122). É importante salientar que Pegenaut também entende a tradução como a produ-

\footnotetext{
${ }^{6}$ Para mais detalhes sobre tradução pedagógica ou como ferramenta didática, vide LUCINDO, 2006.

${ }^{7}$ Para Longo, a tradução também não deve ser empregada nos níveis iniciais de ensino, uma vez que pode sobrecarregar os alunos com informações que não são ainda oportunas. (LONGO, 2011, p. 13)
} 
ção de um texto "que resulte em sua totalidade um equivalente ao original", e não somente a passagem de uma língua à outra (1996, p. 122), estando aptos a traduzir somente aqueles que dispõem de grande conhecimento das línguas envolvidas. Essas premissas são, em certa medida, as que vimos nas especificações do que se denomina tradução no contexto de ensino/aprendizagem de latim, de acordo com alguns métodos didáticos.

Ainda podemos verificar outra nomenclatura no que concerne à tradução de textos latinos. A chamada tradução de serviço, segundo Lima, é uma das maneiras pelas quais se pode compreender tradução do latim:

Isto posto, começo por deixar claro que, tratando-se das línguas antigas, é com pelo menos duas acepções da tradução que se há de trabalhar: 1) a que, considerada a enorme distância em que o tradutor moderno se encontra da vida quotidiana e coloquial do idioma do qual deve traduzir, $o$ obriga ao trabalho, frase a frase, em que, por isso mesmo, o resultado da tarefa de traduzir não se distingue muito da análise ou descrição do sistema gramatical. A esta podemos chamar tradução de serviço, como fazem professores italianos. [...] 2) segundo uma concepção moderna, se pode quem sabe designar por tradução discursivo/textual, ou tradução simplesmente; é aquela que assim se pode definir: "é a procura de um equivalente, e não de um substituto. Requer pelo menos uma afinidade estilística, quando não, psicológica" (BRODSKY, 1994, p.86). (LIMA, 2003, p.13. Grifos nossos.)

Novamente verificamos concepções que se baseiam ora na estrutura gramatical, transmitindo uma ideia de que é preciso verter o texto atentando para esses aspectos para compreendê-lo num primeiro momento, ora em uma determinada noção de equivalência, quando o tradutor ou o aluno deverá fazer as adaptações necessárias para que o texto traduzido dê conta de transmitir as 
mesmas emoções do texto original. No que tange à primeira acepção, a da tradução de serviço, não haveria exigências para sua produção senão "os conhecimentos subministrados pelos gramáticos e gramáticas da tradição e pelas outras obras de referência, no que concerne ao léxico, ou antes, às definições léxicas ali consagradas" (LIMA, 2003, p. 13). Em relação à segunda, entretanto, há de se considerar o êxito da tradução em conservar o estilo e a expressividade do original.

A origem da expressão tradução de serviço, atribuída a Sega e Tappi (1986), é retomada por Longo: “'Traduzione di lavoro’, nella quale se rende esplicito e consciente il ruolo strumentale del tradurre: non per tradurre, ma per capire" (apud LONGO, 2011, p. 68). Ou seja, a tradução se apresenta nesse caso claramente como um instrumento para compreender o texto, mas não pode ser considerada uma tradução propriamente dita uma vez que não corresponderia ao equivalente expressivo do original. Além disso, nesse viés, percebemos que as atividades de interpretação e tradução aparecem desvinculadas na medida em que uma não é tomada como parte do processo da outra. A oposição que observamos, então, entre tradução propriamente dita e tradução de serviço, de referência e de estudo ou operacional para denominar traduções produzidas no contexto de ensino/aprendizagem de latim reflete uma visão de tradução assentada, em certa medida, no estruturalismo, que assume o texto produzido como um possível equivalente (em diferentes níveis) do texto original $^{8}$. A tradução em sala de aula, além disso, ainda parece carregar em si a ideia de tradução literal e preservação do texto original, que são postas em xeque quando saímos das fronteiras do ensino/aprendizagem.

\footnotetext{
${ }^{8}$ Os atributos conferidos pelos autores vistos à tradução didática evocam uma noção de equivalência em tradução que remonta a Eugene Nida (1964), que propôs a dicotomia entre equivalência formal e equivalência dinâmica, presente em diversas teorias da tradução. Segundo Rodrigues (2000), autores como Nida e Catford se ocuparam das ideias de equivalência e correspondência em tradução no campo da Linguística, e outros, como Lefevere e Toury acabaram por abordar, em certa medida, os mesmos conceitos, mas no âmbito da tradução literária
}

Cad. Trad., Florianópolis, v. 37, no 3， p. 139-159, set-dez 2017 
Ora, essas nomeações parecem justamente resguardar a tradução como atividade didática na medida em que ela, muitas vezes, não condiz com as expectativas de uma "tradução poética" ou "tradução criativa", que têm batalhado por seu espaço nos Estudos Clássicos ${ }^{9}$. No entanto, acreditar que essas traduções pedagógicas, ainda que com as suas particularidades, não sejam também recriações é, de certo modo, apagar a atuação dos sujeitos leitores-tradutores discentes da língua latina e desconsiderar que toda tradução é uma tradução, que revela, inclusive, marcas do sujeito que a produz.

\section{Um Breve Exemplo: duas traduções}

Vejamos as seguintes traduções de um passo da Eneida (II. vv. 234-45), em que Eneias narra o evento do cavalo de Troia. A primeira tradução (à esquerda) foi produzida quando aluna de Latim VII, em 2009, e a outra, em 2016, também no contexto didático, mas como estagiária da mesma disciplina ${ }^{10}$ para servir de orientação para as revisões das produções dos alunos:

\footnotetext{
${ }^{9}$ Em relação às tradicionais traduções filológicas, que por muito tempo foram mais valorizadas enquanto tarefa do tradutor dos textos clássicos. Sobre essa questão, vide BERMAN, A. $A$ tradução e a letra ou o albergue do longínquo, trad. Marie-Hélène C. Torres, Mauri Furlan e Andréia Guerrini. Rio de Janeiro: 7 Letras/PGET, 2007, e VASCONCELLOS, 2011.

${ }^{10}$ Disciplina sob responsabilidade da Profa. Isabella T. Cardoso.
} 


\begin{abstract}
druidimus mürös et moenia pandimus urbis. accingunt omnès operi pedibusque rotārum subiciunt läpsūs, et stuppea vincula collō intendunt; scardit fatälis machina müross fêta armìs. puer ì circum inmüptoeque puellae 5 sacr a carunt fünemque manü contingere goudent; illa subit mediceque mināns inläbitur urbì. ō patria, ò dīuum domus İlium et incluta bellō moenia Dardanidum! quater ipsō in līmine portae substitit atque uterō sonitum quater arma dedère- 10 instāmus tamen imnemores caecique furōre et mōnstrum infélitx sacrāta sistimus arce. (Eneida 2.234-45. 0 texto latino segue o apresentado palo livo Aprendendo latim (2012), seçäo 5B, p. 382)
\end{abstract}

\begin{abstract}
Abrimos os muros e revelamos as [construçöes da cidade.

Todos estavam prontos para o trabalho [e fariam escorregar sob as rodase estendiam ligas de estopa no pescoso. A máquina fatal sobe as paredes preth [de amias. Os meninos e as castas as menines ao redor cantam ritos sgados e se alegram ao toca a cordacom as mãos.

A máquina sobe elança-se am eaçadora no meio [da cidade.

Oh pária! Oh ilion, casa dos deuses e muras dos troianos famosos na guerral. Quatrovezes parouna soleira da porta equatro vezes oex ército fez um son de seu [ventre.

Perseguim os, no entanto, os desm en oriadose [os cegos pela loucurai E o monstro destruidor, ànossa sagrada cidade apresentmos
\end{abstract}

\author{
Afrebentarl os os muros e as construçîes da cidade \\ revelamos \\ Todos se preparam para o trabalho, colocan o rolamento \\ sob os pés e no pescoço amarran \\ cordas de estopa; a máquina fatal escala os muros \\ prenhe de $a m a / s o b l a d o s$, maninos ao redor e neninas \\ [dorzelas \\ cantan \\ canções sagradas e se al egram em tocar a corda com a mão. \\ Fla gal ga conoagants/comeagadora e resvala o meio da \\ diade. \\ Ó pátria ó Troia, casa dos deuses, e muros dos troianos, \\ famosos quanto à guerral Quatro vezes subsisto/se cletém \\ ta soleira da porta equatro vezes as armas ressoam no \\ ventre; \\ Insistim os, contudo, imprudentes e, cegos pelo furor; \\ o monstro infausto colocam os na cidacela sagraid.
}

A proposta do material Aprendendo Latim é que o aluno traduza o excerto com o auxílio de um vocabulário que traz, além de uma ou duas acepções para o vocábulo, pistas quanto a complementos, regências etc. que apoiam o aluno na construção do sentido. A presença desse vocabulário não impede que os alunos consultem também o dicionário, obras de referências e mesmo outras traduções, muitas vezes discutidas na sala de aula, a fim de que seja possível observar diferentes soluções tradutórias. As duas traduções oferecidas são produtos de um mesmo sujeito, mas ainda assim são diferentes, como eram as produções dos alunos. 
Diríamos que ambas são literais; no entanto, como definiríamos isso quando apresentam em alguns momentos escolhas lexicais (entre outras) distintas para um mesmo termo latino? Não há, de fato, em nenhuma delas, a preservação do hexâmetro datílico, verso típico da épica, embora exista a tentativa de manter o texto em versos, e até mesmo trabalhar a ordem das palavras, mesmo restando algum estranhamento em português, mas de modo a conservar algo do que se observa no original. Ainda que sejam traduções com o mesmo fim e produzidas num mesmo âmbito pedagógico, elas são reflexo de uma leitura feita em momentos diferentes, são historicamente marcadas a partir dos objetivos definidos para a tradução desses textos - o aprendizado da língua, depois o exercício e a correção. São traduções atreladas à leitura e à interpretação, essa também é feita a partir do arranjo do texto, de um trabalho que o faça ter sentido na LM.

Dentre os pontos que podemos observar no que tange às escolhas em cada tradução, vemos, na primeira, um decalco da conjunção " $e$ " (1. 3) que vem do texto latino, enquanto na segunda opta-se pela inserção de uma vírgula para encadear a sequência de ações. Na segunda tradução, nota-se maior liberdade em repetir os vocábulos em português, assim como ocorre no texto latino, não havendo, portanto, a alternância entre muro e parede (em latim, $m \bar{r} r o ̄ s ; 1.1$ e 6$)$. No que concerne à escolha vocabular, muitas das opções talvez causem estranheza, porém, em 2009, o método era empregado ainda em inglês, de onde talvez decorra a estranha tradução de alguns termos. Além disso, vemos traduções diferentes para incluta bellō, em que se escolheu conscientemente, na segunda tradução, manter uma das sugestões do método para o ablativo de relação: famosos quanto à guerra em lugar de famosos na guer$r a$, tendo em vista que esse foi um tópico gramatical visto em sala de aula. Por fim, verificamos na segunda tradução a presença de dois termos como soluções possíveis (subsiste/se detém), revelando hesitação do aluno-tradutor-leitor, quanto à escolha lexical.

Haja vista essa mudança de leitura e de possibilidades verificadas nos textos, podemos dizer que ambas são traduções. Ainda 
que não revelem opções tidas como as mais plausíveis em relação ao que uma comunidade espera de textos poéticos, revelam uma reflexão, uma escolha, um trabalho: não se trata de uma suposta "transposição", para empregar as palavras de Longo, do texto latino para o português. O resultado dessas escolhas se deve ao sujeito, a seu lugar e ao fato de cada leitura é uma leitura, do mesmo modo é a tradução ${ }^{11}$.

\section{Algumas considerações}

A reflexão acerca desse tema veio do olhar para o exercício de tradução no aprendizado a partir de dois lugares: de estagiária docente e de aluna de latim, dada a atuação nesses dois papéis frente ao ato tradutório durante o ensino/aprendizagem de latim. Do lugar de não-aluna, foi possível perceber que, à medida que lemos o texto latino, atribuímos sentidos a ele, corporificados na tradução. Dessa maneira, observamos a relação entre leitura e tradução no ensino/aprendizagem de latim, que faz do aluno aprendiz um leitor-tradutor ou um tradutor-leitor. À medida em que lê, reflete sobre a linguagem e o modo como é utilizada, acessando um léxico mental já construído, bem como identificando e analisando as estruturas gramaticais conhecidas e aquelas que ainda não fazem parte de seu repertório, mas que serão resolvidas a partir da leitura de outros aparatos e da mobilização de outras competências relacionadas à leitura. Não se trata, portanto, de memorizar estruturas

\footnotetext{
${ }^{11}$ No que concerne à escolha tradutória e à interpretação em diferentes momentos, é interessante notar nas anotações do caderno da primeira tradução que uma das possibilidades aventadas como tradução do sintagma caecīque furōre era "com o furor de um cego", entendendo caecus como adjetivo substantivado (e não como adjetivo, como indica o método). Isso revela possibilidades de leitura do mesmo trecho e a escolha da tradução dependerá do sujeito tradutor e de seus conhecimentos. Nesse caso, o aluno-leitor-tradutor precisaria ir além da estrutura gramatical para perceber o que seria mais adequado, recorrendo, por exemplo, ao contexto. Nos mesmos versos, nota-se na primeira tradução um equívoco em relação ao objeto de "perseguimos", dado pela confusão com os casos das palavras, ainda assim revelando uma leitura
}

Cad. Trad., Florianópolis, v. 37, no 3, p. 139-159, set-dez 2017 
ou decodificar palavra por palavra e traduzi-las. A tradução, nesse sentido, é o produto da leitura, uma vez que aparece como resultado da atribuição de sentido ao texto, ou seja, a tradução e a leitura em latim - no ensino/aprendizagem e no estudo - podem ser vistas como transmutáveis. Nesse exercício didático, o ato de "traduzir é uma leitura-escrita”, emprestando uma ideia de Plessard (2007, p. 20-21). A leitura e a tradução se alternam, portanto, em momentos de interpretação do texto de partida, apropriação e releitura do texto produzido ao final - a tradução. Ademais, para a tradução dos textos, a leitura estará presente também em outros eventos, como na consulta a dicionários e na pesquisa de outras fontes, uma vez que situar o texto e seu contexto faz parte da ativação da competência de leitura ${ }^{12}$.

Se a leitura e a tradução estão de tal maneira imbricadas no trato com o texto latino e se a retextualização do sentido produzido ocorre via tradução, podendo essa, então, ocupar o papel/ função de possibilitar ao aluno a restituição de "um texto tão contextualizado quanto possível, em sua globalidade e levando em consideração as especificidades da escrita de um autor particular" (PLESSARD, 2007, p.15), durante seu estudo, o aprendiz produz uma tradução e, nesse sentido, uma leitura. Essa tradução pode apresentar especificidades, tendo em vista seu contexto de produção. O que ocorre, muitas vezes, em relação aos discentes de latim que se encontram nos últimos níveis de aprendizado, é que são capazes de produzirem traduções de adaptados ou de originais, mas essas produções em muitos momentos não são consideradas uma tradução propriamente dita, pois que são vistas um exercício de leitura ou de estudo e por não serem "expressivas".

\footnotetext{
${ }^{12}$ As competências de leitura são as mesmas, é possível dizer, que compõem a competência tradutória. Quando se fala de competência tradutória, dentre as diversas acepções que encontramos, Pym apresenta a de Hurtado, que "divide a competência tradutória em linguística, extralinguística, textual (compreensão e produção), "habilidades profissionais" gerais e "competência de transferência" (2008, p. 17), ou mesmo como "somatória" de diversos conhecimentos, como das línguas, dos gêneros, da cultura, das estratégias etc. (Cf. BELL, 1991 apud PYM, 2008, p. 17). No entanto, hoje, também se costuma pensar a competência tradutória em termos de mercado e uso de tecnologias (PYM, 2008).
} 
Por isso, é comum encontrar algumas adjetivações da tradução em latim que aparecem notadamente nesse contexto, como tradução de serviço, tradução de referência e tradução operacional ou de estudo. Tais especificações revelam certo cuidado, por parte dos estudiosos da área, desde os aprendizes até aqueles reconhecidos, ao se falar desses "tipos" tradução em contraste à tradução propriamente dita. É exatamente esse "resguardo" do termo tradução, e consequentemente de seus produtores, no âmbito pedagógico, que nos chama a atenção. Se o aluno lê o texto, com o auxílio de outros aparatos, e não "descobre" o sentido, mas o "constrói” pouco a pouco, o texto já não é o mesmo, existe uma interpretação e, também, uma tradução, um outro texto.

Desse modo, quando verificamos as traduções de referência ou de estudo sugeridas por Longo (2014) e Amarante (2013) em seus trabalhos, bem como as apresentadas como exemplo, percebemos que não são meras transposições linguísticas. Há, com efeito, um trabalho nessas traduções: que seja um mínimo traço estilístico, ou uma escolha vocabular que talvez não seja a primeira acepção do dicionário, por exemplo. Sua literalidade ou proximidade do original não é irrefletida nem única. Ainda que tenham como objetivo dar ênfase a certo aspecto do texto (o linguístico, no caso), buscando certa "equivalência", revelam uma escolha do tradutor. Conforme coloca Rodrigues,

\begin{abstract}
os valores expressos pela tradução não são neutros, sempre há algum tipo de interferência por parte do tradutor, já que suas escolhas não são isentas. Revelam sempre uma avaliação de sua própria língua e cultura, da língua e da cultura estrangeira, assim como do texto e do autor que traduz. (RODRIGUES, 2000, p. 225)
\end{abstract}

Não negamos que para traduzir é preciso o conhecimento linguístico, um domínio razoável das estruturas sintáticas e do vocabulário, ou seja, é necessário estar familiarizado com a língua. 
Além disso, é necessário lançar mão de outras competências, como a textual, a intertextual, a retórica etc. a fim de que se compreenda o texto e que se possa retextualizá-lo via tradução. No entanto, a tradução pode ser realizada por um sujeito que está em curso de aquisição e aprimoramento dessas competências e será uma tradução. Entendemos que quando denominamos uma tradução de tradução de serviço, de referência ou operacional ou de estudo, há um "apagamento", talvez inconsciente, do sujeito como produtor de sentido e responsável pelo texto que produz. Não obstante as intenções de aproximação da literalidade do texto original e de produção de seu equivalente, cada uma dessas "versões" ou "transposições" terão suas singularidades a depender do sujeito; ou seja, não serão exatamente iguais: são, então, traduções marcadas por um sujeito, por um contexto etc.

Além do sujeito, é preciso considerar que os textos, mesmo os latinos, e seus significados não são estáveis. Arrojo (1992) coloca em xeque a ideia de tradução como transferência de significados ao apontar a inerente subjetividade do tradutor-leitor que é, conforme descreve Travaglia, o que "produz os significados e não o que retira os significados 'a priori' presentes no texto. Isso faz com que se possa entrever o texto como o lugar privilegiado do diálogo, onde o leitor, seu tempo e seu espaço têm papel essencial" (2003, p. 55). Não pretendemos aqui que o leitor-tradutor tenha plena liberdade ao lidar com o texto, na medida em que, com efeito, esse tem seu papel, trazendo possibilidades de sentido além de funcionar como um "arranjo de marcadores". Segundo Travaglia, a língua e o texto estabelecem regras para a leitura que, combinados "com toda a experiência do leitor, provoca a construção dos sentidos" (TRAVAGLIA, 2003, p. 55).

Nesse sentido, ainda que uma tradução tenha o intuito de dar visibilidade à análise e aos aspectos gramaticais do latim, que seja feita no trabalho frase a frase, sem considerar, por exemplo, aspectos poéticos ou outros, ela só se dá a partir de uma experiência leitora; essas marcas são as que vemos como sujeito-leitor-tradutor e, com isso, construímos sentidos. Arrojo (1992) tece relações quanto 
aos atos de compreender, de interpretar e a tradução. Questionando a visão logocêntrica da interpretação, sobretudo na área da tradução, que pressupõe que os significados são recuperados nos textos por um leitor que o compreendeu corretamente, a autora defende que a tradução produzirá novos sentidos, dada a atuação sujeito tradutor. Segundo ela,

toda tradução, por mais simples e breve que seja, trai sua procedência, revela opções, as circunstâncias, o tempo e história de seu realizador. Toda tradução, por mais simples e breve que seja, revela ser produto de uma perspectiva, de um sujeito interpretante e, não, meramente, uma compreensão "neutra" e desinteressada ou um resgate comprovadamente "correto" ou "incorreto" dos significados supostamente estáveis do texto de partida. (ARROJO, 1992, p. 68)

Arrojo procura desconstruir a ideia de interpretação neutra, de resgate de significados em prol de uma teoria da tradução que tome o sujeito-tradutor como produtor de sentidos. Para ela, "qualquer tradução denuncia sua origem numa interpretação, ainda que seu realizador não a assuma como tal" (ARROJO, 1992, p. 78). Na medida em que categorizamos as traduções no contexto pedagógico em latim (produzida por estudantes ou professores), parece-nos que as isentamos de responsabilidades, uma vez que somos conscientes das exigências que se fazem para autorizar uma ou outra tradução, sobretudo em se tratando de textos literários, dos quais se espera, em geral, algo criativo, com cuidados estéticos, por assim dizer. Contudo, como pontua Arrojo,

[a]prender a traduzir, tornar-se tradutor, implica, portanto, em primeiro lugar, reconhecer seu papel essencialmente ativo de produtor de significados e de representante e intérprete do autor e dos textos que traduz. Além desse reconhecimento, é claro, cabe ao tradutor assumir a respon- 
sabilidade pela produção de significados que realiza e pela representação do autor a que se dedica. Ou seja, terá que estar sintonizado com o ideário de seu tempo e lugar e, consequentemente, com a visão que esse tempo e lugar lhe permitem ter do texto e do autor que interpreta. (ARROJO, 1992, p. 103-4)

Ocorre que o uso das expressões de serviço, de referência, operacional etc., ainda que num primeiro momento tenham sido empregadas a partir de um lugar teórico, e que revelem a distinção entre interpretar e traduzir, tornou-se natural na área de Estudos Clássicos. Não raramente, conferimos essas designações, especialmente de serviço, àquelas traduções que produzimos para uma aula, um trabalho ou para um congresso, enfim, que são postas a público. São textos que, embora tenham sido trabalhados, podem não dar conta de aspectos literários, ou de características do autor, e poderiam não ser legitimados dentro da comunidade acadêmica como uma "tradução literária" ou "tradução criativa". Contudo, essas simples denominações, nos parece, além de resguardar o tradutor da responsabilidade daquele texto produzido, desvaloriza também seu empenho com o texto latino.

Desse modo, a tradução no contexto do ensino/aprendizado do latim, considerando uma abordagem textual de ensino com a leitura, é vista como ferramenta de interpretação do texto, distinguindo-se da tradução feita como objetivo em si mesma. Nesse sentido, pudemos observar tal distinção por meio de atributos ao termo tradução: as denominadas tradução de referência, tradução de estudo, tradução operacional e tradução de serviço em contraposição à tradução propriamente dita e à tradução simplesmente, um etapa posterior e que requere conhecimentos mais abrangentes da língua, da cultura, etc. Tendo em vista tais usos e a concepção dessa tradução pedagógica como processo de interpretação do texto, acreditamos que mesmo essa tradução, com seus objetivos, quando a observamos do prisma de Teorias da Tradução, pode ser considerada também "tradução", na medida em que é produto de 
uma leitura, de uma interpretação, de um sujeito em determinado contexto e momento histórico.

\section{Referências}

AMARANTE, J. Dois tempos da cultura escrita em latim no Brasil: o tempo da conservação e o tempo da produção: discursos, práticas, representações proposta metodológica. Tese de Doutorado em Língua e Cultura. Instituto de Letras, UFBA, Bahia, 2013.

Latinitas: leitura de textos em língua latina. Vol. I e II. Bahia, 2015. Disponível em: www.latinitas.ufba.br. Acesso em 30/08/16.

ARROJO, R. Compreender x interpretar e a questão da tradução. In: (Org.). O signo desconstruído: implicações para a tradução, a leitura e o ensino. Campinas: Pontes, 1992.

. O ensino da tradução e seus limites: por uma abordagem menos ilusória. In:___ (Org.). O signo desconstruído: implicações para a tradução, a leitura e o ensino. Campinas: Pontes, 1992.

FERNANDES, T. A tradução e o ensino de latim. 2010. Dissertação de Mestrado em Estudos da Tradução. Centro de Comunicação e Expressão, UFSC, Santa Catarina.

. Alguns Problemas Teóricos da Tradução de Línguas Antigas: Reflexões Acerca das Dificuldades do Tradutor do Latim. Scientia Traductionis, Florianópolis, n. 10, p. 80-89, jan. 2011. Disponível em: https://periodicos.ufsc. br/index.php/scientia/article/view/1980-4237.2011n10p80/19988\%3E. Acesso em: 23 out. 2016.

FORTES, F. O ensino de latim centrado no uso da língua e na aquisição de competências. Phaos, n. 13, p. 7-21, 2013.

FORTES, F.; PRATA, P. Ensino de latim: Abordagens metodológicas e leitura. In: . (Orgs.), O Latim hoje: reflexões sobre cultura clássica e ensino.

Campinas: Mercado de Letras, p. 89-118, 2015. 
JAKOBSON, R. Linguística e Comunicação. Trad. Izidoro Blikstein e José Paulo Paes. São Paulo: Cultrix, 2008.

JONES, P. V.; SIDWELL, K. C. Aprendendo latim: textos, gramática, vocabulário, exercícios, tradução e supervisão técnica. Isabella T. Cardoso, Paulo S. de Vasconcellos. São Paulo: Odysseus Editora, 2012.

LIMA, A. D. Possíveis correspondências expressivas entre latim e português: reflexões na área da tradução. Itinerários, n. especial, p. 13-22, 2003.

LONGO, G. Ensino de Latim: problemas linguísticos e uso de dicionário. 2006. Dissertação de Mestrado em Linguística e Língua portuguesa. Faculdade de Ciências e Letras, UNESP, Araraquara.

. Ensino de latim: reflexão e método. 2011. Tese de Doutorado em Linguística e Língua portuguesa. Faculdade de Ciências e Letras, UNESP, Araraquara. $\overline{188,20} 14$.

. A abordagem textual no ensino de latim. Organon, v. 29, n. 56, p. 175-

LUCINDO, E. S. Tradução e ensino de línguas estrangeiras. Scientia Traductionis, Florianópolis, n. 3. Disponível em: https://periodicos.ufsc.br/index.php/scientia/ article/view/12933 . Acesso em: 30 ago. 2016.

MIOTTI, C. M. O ensino de latim nas universidades públicas do estado de São Paulo e o método inglês Reading Latin: um estudo de caso. 2006. Dissertação de Mestrado em Linguística. Instituto de Estudos da Linguagem, Unicamp, Campinas.

PEGENAUT, L. La traducción como herramienta didáctica. Contextos, v. XIV, n. 27-28, pp. 107-125, 1996.

PLASSARD, F. Lire pour traduire. Paris: Presses Sorbonne Nouvelle, 2007.

PYM, A. Redefinindo competência tradutória em uma era eletrônica. Em defesa de uma abordagem minimalista. Cadernos de Tradução, Florianópolis, v. 1, n. 
21, p. 9-40, 2008. Disponível em: https://periodicos.ufsc.br/index.php/traducao/ article/view/8197/7579. Acesso em: 30 ago. 2016.

RODRIGUES, C. C. (2000). Tradução e diferença. São Paulo: Editora UNESP.

TRAVAGLIA, N. G. (2003). Tradução retextualização: a tradução numa perspectiva textual. Uberlândia: EDUFU.

VASCONCELlOS, P. A Tradução Poética e os Estudos Clássicos no Brasil de Hoje: Algumas Considerações. Scientia Traductionis, Florianópolis, n. 10, p. 68-79, jan. 2011. Disponível em: https://periodicos.ufsc.br/index.php/scientia/ article/view/1980-4237.2011n10p68. Acesso em: 23 out. 2016.

Recebido em: 23/03/2017

Aceito em: 15/07/2017

Publicado em setembro de 2017 